\title{
MOLDES Y OTROS ÚTILES PROCEDENTES DEL ALFAR TARDORROMANO DE SOBREVILLA (BADARÁN, LA RIOJA)
}

\author{
Pilar Pascual Mayoral ${ }^{1}$ \\ Instituto de Estudios Riojanos \\ pilarpascual02@gmail.com \\ Pedro García Ruiz ${ }^{2}$ \\ Instituto de Estudios Riojanos \\ pedrogruiz02@gmail.com \\ Miguel Ángel Pascual Mayoral ${ }^{3}$ \\ Instituto de Estudios Riojanos \\ Luis Argaiz Velasco ${ }^{4}$ \\ Instituto de Estudios Riojanos
}

RESUMEN: La abundante presencia de terra sigillata hispánica tardía recuperada en asentamientos del bajo imperio contrasta con el escaso conocimiento de los centros productores de este tipo de vajilla, circunstancia que inevitablemente ralentiza el estudio general de esta apasionante secuencia cultural. Damos a conocer en este artículo un conjunto de materiales arqueológicos, compuesto por ciento treinta y un fragmentos de molde y otros útiles propios de este gremio alfarero, con los que esperamos favorecer nuevos estudios sobre la actividad industrial del centro alfarero de Sobrevilla y las rutas comerciales de sus producciones. Planteamos, además, la hipótesis de la presencia de varios nuevos alfareros; identificables a través de las diferentes marcas que han dejado impresas en sus moldes.

1. PASCUAL MAYORAL, María Pilar. Arqueóloga. Investigadora del Instituto de Estudios Riojanos. pilarpascual02@gmail.com

2. GARCÍA RUIZ, Pedro. Etnografía. pedrogruiz02@gmail.com

3. PASCUAL MAYORAL, Miguel Ángel. Autor de los dibujos.

4. ARGAIZ VELASCO, Luis. Infografía. 
Palabras clave: Sobrevilla, moldes, alfar, terra sigillata hispánica tardía, grafitos, marcas de alfarero.

\title{
MOULDS AND OTHER TOOLS FROM THE LATE ROMAN POTTERY WORKSHOP OF SOBREVILLA (BADARÁN, LA RIOJA, SPAIN)
}

\begin{abstract}
The numerous finds of Hispanic terra sigillata at Late Roman settlements contrasts with the little knowledge as to the centres that produced this type of tableware. This has inevitably limited surveys of this compelling subject. The current article examines an assemblage of 131 fragments of moulds and other tools characteristic of this Late Roman industry so as to shed new light on the question, in particular on the distribution of the products from the Sobrevilla workshop.

We also hypothesize the presence of several potters, identified by the different potter stamps that they have left imprinted on their moulds.
\end{abstract}

Keywords: Sobrevilla, moulds, pottery production, Late Roman Hispanic terra sigillata, graffiti, potter stamps.

Recibido: 15 de marzo de 2021 Aceptado: 25 de noviembre de 2021

\section{Introducción}

En el año 1985 José Ramón López Rodríguez publicó la tesis doctoral: Terra sigillata hispánica tardía decorada a molde en la Península Ibérica. Aquel brillante trabajo de investigación basado en la visita a buena parte de los museos españoles y portugueses, más el estudio de anteriores publicaciones entre las que cabe destacar las de María Ángeles Mezquíriz y Pedro de Palol, así como las memorias de varias excavaciones arqueológicas y la consulta de colecciones particulares, permitió catalogar dos mil trescientos fragmentos cerámicos asociados a esta secuencia cultural ${ }^{5}$.

La información obtenida fue escrupulosamente inventariada y posteriormente publicada pero las escasas evidencias de elementos imprescindibles en el ámbito alfarero, como son los moldes para la fabricación de vajilla decorada, le impidieron establecer la ubicación de los principales centros productores y por tanto conocer las rutas utilizadas durante la comercialización de aquellas producciones.

5. José Ramón LÓPEZ RODRÍGUEZ: Terra sigillata hispánica tardía decorada a molde en la Península Ibérica, Valladolid, Secretariado de Publicaciones, Universidad, 1985. 
En los últimos años, no podemos olvidar los trabajos que se han publicado sobre terra sigillata hispánica tardía y que van aportando luz sobre estas producciones, citar a J.C. Paz Peralta ${ }^{6}$, a M.V. Romero Carnicero ${ }^{7}$ y el más reciente de F. Pérez Rodríguez-Aragón ${ }^{8}$, este último hace mención expresa de los testimonios de alfares de la cuenca media del río Najerilla.

También se han realizado nuevas publicaciones sobre alfares tardorromanos en la zona media del Najerilla, pero los materiales estudiados, aunque importantes son insuficientes para precisar la importancia industrial de esta zona de La Rioja.

Treinta y cinco años después de la obra publicada por López Rodríguez, gracias a las prospecciones visuales realizadas por Hilario Pascual González, Pedro Rioja Rubio y otros vecinos de Badarán, damos a conocer en este artículo un inventario compuesto por ciento treinta y un fragmentos de molde para la fabricación de TSHT y algunos útiles asociados al ámbito alfarero, procedentes todos ellos del yacimiento tardorromano de Sobrevilla.

Así como la posibilidad de poder afirmar la presencia de varios alfareros gracias a las marcas impresas en los fragmentos de moldes hallados y que sirven indudablemente para demostrar la propiedad de los mismos y que permite precisar su pertenencia a una persona concreta.

\section{Principales noticias del yacimiento de Sobrevilla}

Hacia el año 1930 se crea el Museo Catequístico de Calahorra (La Rioja) y poco tiempo después el Boletín Diocesano de Calahorra publica las primeras noticias de su existencia ${ }^{9}$.

En 1931 asume la dirección de este museo Julio Rodríguez Gracia, multiplica los fondos existentes sobre el arte sacro de la diócesis y crea, entre otras actividades más, un equipo de prospección arqueológica.

6. Juan Ángel PAZ PERALTA: Cerámica de mesa romana de los siglos III al VI d.C. en la provincia de Zaragoza, Zaragoza, Institución Fernando el Católico, 1991.

7. María Victoria ROMERO CARNICERO et al:: "El centro de producción de cerámica de Uxama (Osma/El Burgo de Osma, Soria)", en Société Française d'Étude de la Céramique Antique en Gaule (SFECAG): Actes du Congrès de L'Escala-Empúrie, Marseille, SFECAG, 2008, pp. 319-330.

8. Fernando PÉREZ RODRÍGUEZ-ARAGON: “La 'terra sigillata' Hispánica Tardía: Una propuesta de sistematización", en Carmen FERNÁNDEZ OCHOA, Ángel MORILLO CERDÁN y María del Mar ZARZALEJOS PRIETO (coords.): Manual de la cerámica romana. IV producciones cerámicas de época medio imperial y tardorromana, Madrid, Museo Arqueológico de la Comunidad de Madrid, Colegio de Doctores y Licenciados en Filosofía y Letras y en Ciencias de la Comunidad de Madrid, 2019, pp. 65-134.

9. Felipe ABAD LEÓN: Historia viva del Seminario nuevo de Logroño: 75 años dando buen fruto, Logroño, Diócesis de Calahorra y La Calzada-Logroño, 2004, pp. 219 y ss. 
En el año 1970 la noticia de esta iniciativa llega a oídos de Alejandro Marcos Pous, que había realizado algunas excavaciones arqueológicas en la ciudad romana de Libia (Herramélluri) entre otros lugares de La Rioja.

El profesor Marcos Pous informó a María Amor Berigistáin y Amparo Castiella quienes decidieron estudiar los materiales depositados en el seminario logroñés; las conclusiones de sus investigaciones fueron publicadas en el año $1973^{10}$.

Aquel primer artículo aportó amplia información sobre varios yacimientos arqueológicos de La Rioja, aunque más abundantes los de época prehistórica; sobre el asentamiento de Sobrevilla citan de manera escueta "un yacimiento romano en el que aparecían tégulae, ímbrices y terra sigillata" ${ }^{11 .}$

Era esta la primera noticia. Y a ella se referirán años después historiadores del arte y arqueólogos ${ }^{12}$, asociando Sobrevilla a una villa romana ya que las evidencias impedían imaginar en aquel momento la existencia de un alfar.

"Los moldes son elementos imprescindibles que permiten obtener una obra múltiple cuya distribución ofrece al investigador la posibilidad de estudiar las rutas comerciales con algo más de seguridad que si de otro tipo de cerámicas se tratase", comentaba López Rodríguez al describir la importancia de estos fragmentados vestigios ${ }^{13}$.

Efectivamente, el molde es pieza fundamental para el estudio de las producciones de cerámica romana decorada y por tanto imprescindible para detectar un alfar o la presencia de restos de hornos. Desgraciadamente, en su tesis doctoral solo pudo consultar veintidós ejemplares, escasos para establecer la ubicación de cualquier centro productor de cierta entidad.

Y decía poco después: "no son suficientes los moldes encontrados debido probablemente a la escasa prospección y a la carencia de excavaciones, pero no hace mucho tiempo era esta una cifra impensable ${ }^{\prime 14}$. De aquellos veintidós ejemplares procedían de la cuenca del Najerilla seis: uno de EstoIlo, dos de Nájera y tres de Tricio.

En la década de 1990 Juan Carlos Sáenz Preciado visitó en Badarán a Pedro Rioja para conocer su colección de materiales arqueológicos, donde se incluían varios fragmentos de terra sigillata hispánica tardía y "un molde decorado fe-

10. María Amor BERIGISTAIN GÚRPIDE y Amparo CASTIELLA RODRÍGUEZ: “La colección Julio Rodríguez del Seminario Diocesano de Logroño", en Javier CAÑADAS SAURA (coord.): Miscelánea de arqueología riojana, Logroño, Instituto de Estudios Riojanos, 1973, pp. 163-196.

11. Ibid., p. 194.

12. María Pilar PASCUAL MAYORAL, P. RIOJA RUBIO y Pedro GARCÍA RUIZ: "El centro alfarero de Sobrevilla. Badarán, La Rioja", Antigüedad y Cristianismo: Monografías históricas para la Antigüedad Tardía, 17 (2000), pp. 291-312, esp. pp. 291-294.

13. José Ramón LÓPEZ RODRÍGUEZ: Terra sigillata hispánica..., p. 42.

14. Ibid., p. 44. 
chado en el siglo $\mathrm{V}$, con grandes círculos dobles de trazo grueso y rosetas de gran tamaño", el yacimiento lo sitúa en término de Badarán pero no confirma el lugar exacto de su ubicación ${ }^{15}$.

En el curso 1997 - 1998 la Universidad de La Rioja puso en marcha el Proyecto OTRI OTAL 970625, Ordenamiento de los Bienes de Interés Cultural e Históricos depositados en el Ayuntamiento de Badarán (La Rioja), cuyo objetivo consistía en la ordenación y catalogación de los materiales depositados en el museo municipal. Los trabajos fueron dirigidos por el profesor de Prehistoria J. A. Santos Velasco y financiados por este ayuntamiento riojano.

En 1999 el equipo universitario publica un resumen de aquel proyecto. Sobre el yacimiento de Sobrevilla fue documentado un lote de TSH y TSHT, y cuatro pequeños fragmentos de molde para la producción de sigillata tardía ${ }^{16}$.

Esta parte del proyecto se completará con el estudio de un ejemplar de columna de piedra arenisca, de cronología imperial; corresponde a la parte superior de una columna que presenta capitel toscano.

En el fuste quedó grabada una inscripción que según Castillo Pascual dedicó Emilius Quintilianus, posible morador de este enclave, a las Matres Apillarae ${ }^{17}$. Y hay que destacar también el hallazgo de un antoniano del emperador Galiano, fechado entre 253 y 268 d.C., por su aportación cronológica ${ }^{18}$.

En aquellas fechas estaba en prensa la noticia del hallazgo de un fragmento de molde decorado a mano alzada procedente también de Sobrevilla, cuya escena es relacionada con las diosas Diana - Artemis $^{19}$.

Con esta última noticia quedaba confirmada la existencia de un centro alfarero productor de TSHT en Sobrevilla, donde según los vestigios localizados durante una meticulosa prospección de superficie, en la que se localizaron adobes quemados, cenizas y fragmentos de molde, se planteó la posible existencia de hasta siete hornos alfareros ${ }^{20}$.

Durante la entrega al Ayuntamiento de Badarán del estudio realizado, un grupo de vecinos informó a los arqueólogos de la Universidad de La Rioja sobre la existencia de nuevos vestigios procedentes de varios yacimientos de la zona.

15. Juan Carlos SÁENZ PRECIADO: "Los alfares de época tardorromana del valle del río Najerilla (siglos IV - VI d. C)", Berceo, 128 (1995), pp. 113-157, esp. p. 124.

16. Milagros MARTíNEZ GONZÁLEZ y Saúl VITORES BAÑARES: "Yacimientos romanos en los entornos de Berceo y Badarán (La Rioja)", Iberia: Revista de la Antigüedad, 2 (1999), pp. 239-273, esp. pp. 250-258.

17. María José CASTILLO PASCUAL: “Una dedicatoria a las Matres en Badarán (La Rioja)", Hispania Antiqua, 23 (1999), pp. 137-141.

18. Ibid., p. 139.

19. María Pilar PASCUAL MAYORAL, P. RIOJA RUBIO y Pedro GARCÍA RUIZ: "El centro alfarero de Sobrevilla...", pp. 291-312.

20. Ibid., p. 296. 
Entre los nuevos materiales entregados había cerámica estampillada, terra sigillata hispánica tardía decorada y varios fragmentos de molde para su fabricación ${ }^{21}$.

\section{Localización geográfica del yacimiento}

El yacimiento romano de Sobrevilla se localiza al este del núcleo urbano de Badarán, a unos setecientos setenta metros de la iglesia parroquial.

Asoma al río Cárdenas que lo limita por el lado norte, mientras la carretera comarcal LR-205 lo hace por el sur. (fig. 1).

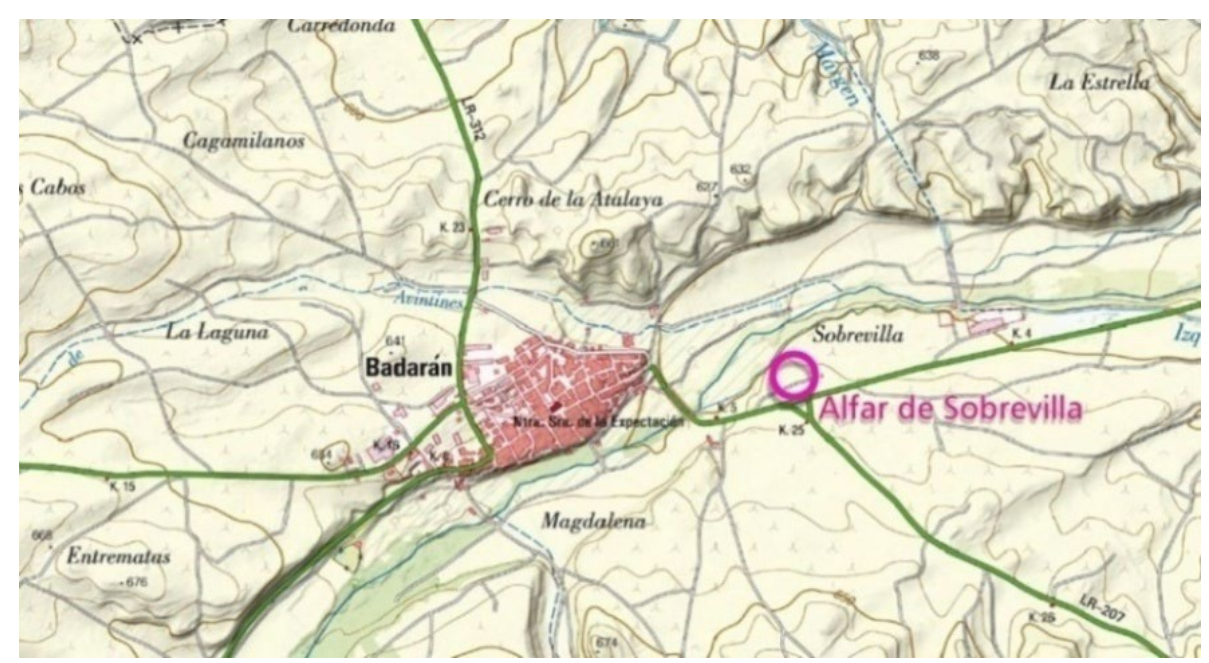

Figura 1. Situación del alfar de Sobrevilla al este de Badarán.

\section{Contexto geográfico e histórico}

Tras la pacificación del valle del Ebro Augusto construye una importante red de calzadas; la vía número uno del Itinerario de Antonino "de Italia in Hispanias", atravesaba el territorio actual de La Rioja de este a oeste ${ }^{22}$.

21. Milagros MARTíNEZ GONZÁLEZ y Saúl VITORES BAÑARES: "Nuevos alfares de "Terra Sigillata" hispánica tardía en el entorno de Tritium Magallum (Badarán y Berceo, La Rioja)", Iberia: Revista de la Antigüedad, 3 (2000), pp. 333-372, esp. pp. 344-349.

22. José Manuel ROLDÁN HERVÁS: Itineraria Hispana: Fuentes antiguas para el estudio de las vías romanas en la Península Ibérica, Valladolid, Departamento de Historia Antigua, Universidad de Valladolid, 1975, pp. 35-42. 
La ciudad de Tritium era el principal enclave de la zona que estudiamos, y en torno a ella surgirá un extraordinario emporio alfarero cuyas producciones serán comercializadas en Hispania, el norte de África y otras zonas de Europa.

A partir del siglo III comienza la decadencia del Imperio romano, situación que se agravará con las devastadoras revueltas bagaudas. Suponemos que la violencia generada por estos acontecimientos no afectó directamente a los habitantes de Tritium, pero sus consecuencias repercutieron negativamente en la comercialización de sus producciones cerámicas, importantísima actividad para su población en aquel momento.

Como sucedió en otros valles de La Rioja, la nueva situación provocó la dispersión de ciudadanos tritienses, parte de los cuales atravesaron el río Najerilla para establecerse en el cerro donde más adelante se levantará el castillo de Nájera, mientras otros buscaban lugares más seguros hacia el sur, alejados de la gran calzada, aguas arriba del río y en las márgenes de sus principales afluentes.

El río Cárdenas fue uno de los afluentes elegidos. Sus terrazas fluviales eran idóneas para establecerse, gracias a las ventajas que ofrecían para la explotación agrícola, y es razonable pensar que entre los nuevos pobladores llegaran a esta zona algunos alfareros que hasta entonces formaron parte de la extraordinaria industria tritiense.

Suponiendo que fuese así, serían aquellos artesanos recién llegados los que construyeron junto a la villa imperial de Sobrevilla los nuevos hornos, donde comenzará la producción de una cerámica diferente: la terra sigillata hispánica tardía.

Pero no fue este el único centro productor de sigillata tardía en la zona, dado que en su entorno van apareciendo enclaves alfareros en jurisdicción de Badarán, Cañas, Berceo o Estollo ${ }^{23}$, y aparecerán probablemente en otros lugares del valle.

\section{Los alfareros de Sobrevilla}

Antes de dar a conocer el listado de los alfareros localizados consideramos oportuno comentar algunas particularidades de los fragmentos de molde estudiados, ya que en sus zonas lisas aparecen vestigios ajenos a la posterior decoración de los vasos.

Se trata de marcas impresas sobre el barro fresco (precocción) o realizadas con incisión después de cocer el molde (postcocción), que desde nuestro punto de vista fueron creadas para mostrar la propiedad del molde.

23. Milagros MARTíNEZ GONZÁLEZ y Saúl VITORES GONZÁLEZ: "Nuevos alfares...", pp. 333-371. 


\subsection{El alfarero Cardius}

Se trata de un fragmento de molde decorado a mano alzada precocción con escena mitológica, delimitada por moldura en el borde. Conserva busto femenino con diadema o creciente lunar, ciervo y pájaro, conjunto decorativo asociado a las diosas Artemis - Diana. Al dorso, es legible entre molduras la firma incompleta CARDIVS, grafitada con técnica de incisión postcocción ${ }^{24}$ (Fig. 2).

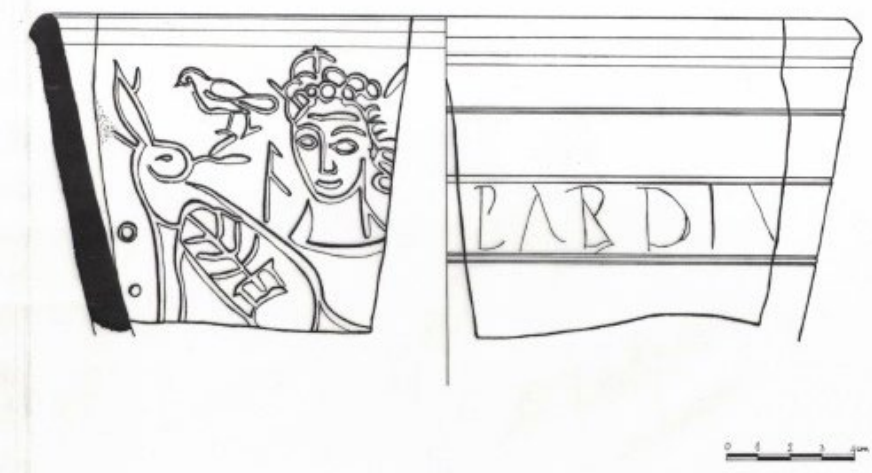

FIGURA 2. Fragmento firmado por el alfarero CARDIVS. Molde 1. Figura 12.

\subsection{El alfarero del grafito}

El segundo ejemplar es un fragmento de molde para la fabricación de TSHT, publicado en el año $2000^{25}$. Se describe como "un fragmento de molde del Primer Estilo que forma la alternancia de rosetas de diez pétalos y un elemento vertical de difícil clasificación".

El posterior hallazgo de un pequeño fragmento de molde, que en su parte superior conserva un similar motivo decorativo, permite describirlo como un punzón vertical de separación que alterna con rosetas decapétalas, cuyos extremos fueron rematados con elementos vegetales ${ }^{26}$ (fig. 3).

24. María Pilar PASCUAL MAYORAL, P. RIOJA RUBIO y Pedro GARCíA RUIZ: "El centro alfarero de Sobrevilla...", pp. 311-312.

25. Milagros MARTíNEZ GONZÁLEZ y Saúl VITORES BAÑARES: "Nuevos alfares...", p. 347. Se acompaña dibujo en p. 351.

26. Agradecemos a David Bolaños Carmona, responsable del Museo de Badarán, la noticia del hallazgo. 
Y se dice a continuación: "en la parte inferior aparece un grafito escrito en letra capital romana del que solo resultan legibles las dos últimas letras (I E)". Pero nada se comenta sobre el motivo que llevó al alfarero a crear este grafito, ni sobre su función (fig. 4).

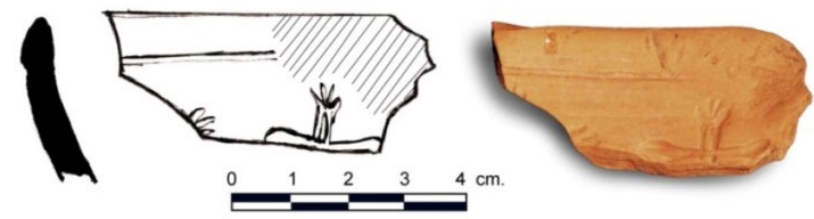

Figura 3. Fragmento con la parte superior del motivo vertical. Molde 69. Figura 32.

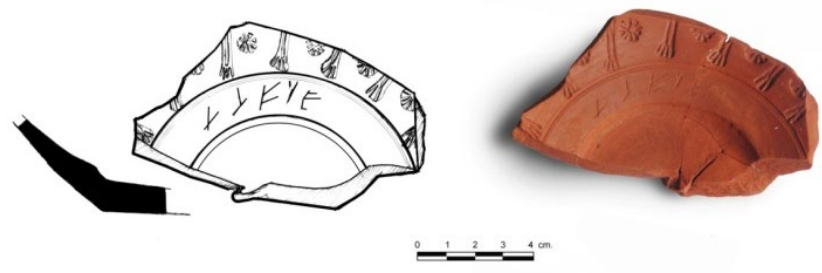

Figura 4. Fragmento firmado por el "alfarero del grafito". Molde 70. Figura 32.

Consideramos que el grafito en cuestión es realizado por el alfarero probablemente para precisar la propiedad del molde. No somos especialistas en epigrafía, pero expertos consultados nos dicen que son varias las posibilidades de interpretación, y que incluso puede tratarse de pseudoescritura.

\subsection{El alfarero del compás}

La decoración a base de círculos y semicírculos es una constante en los alfares tardorromanos, hasta el punto de haber sido clasificada en un grupo específico denominado Segundo Estilo. Este molde presenta decoración parcial de círculos concéntricos dobles, con hileras interiores de medias lunas (fig. 5). 

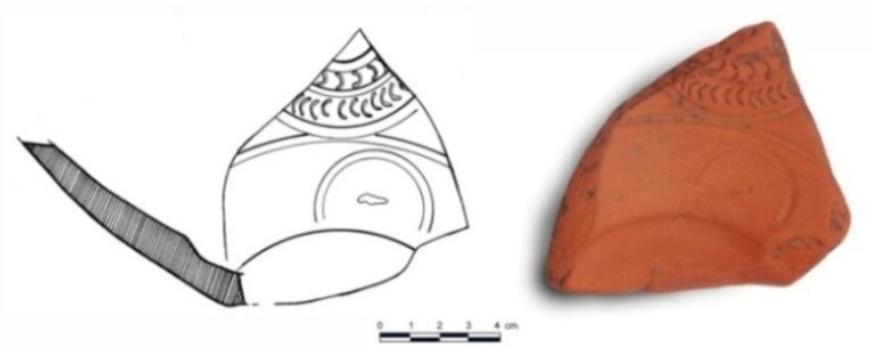

Figura 5. Fragmento con marca de círculo precocción. Molde 54. Figura 27.

En este caso el alfarero crea un círculo precocción como marca de propiedad. No es visible en su totalidad, debido probablemente a que el compás pierde apoyo al llegar al fondo del molde.

\subsection{El alfarero de la roseta decapétala}

El cuarto ejemplar es un fragmento de molde con pequeños motivos decorativos del Segundo Estilo (fig. 6). Conserva una pequeña parte decorada y fue publicado también en el año $2000^{27}$.

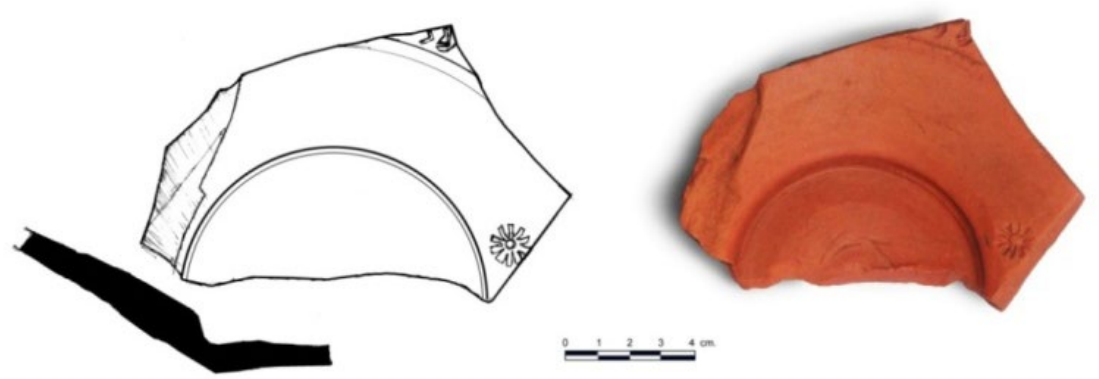

Figura 6. Fragmento con marca de roseta. Molde 71. Lámina 32.

Se describe como "un fragmento de molde con moldura que lo divide en dos partes, en cuya zona inferior aparece una roseta de diez pétalos con círculo central marcado. En el friso superior se aprecia parte de una hilera de ángulos o medias lunas" ${ }^{\prime 28}$. Tampoco en este caso se comenta la creación de

27. Milagros MARTíNEZ GONZÁLEZ y Saúl VITORES BAÑARES: "Nuevos alfares...", p. 346. Se acompaña dibujo en p. 351.

28. Ibid. 
la roseta ni su función, punzón que relacionamos también con la propiedad del molde.

\subsection{El alfarero de la doble aspa}

Ejemplar con decoración perteneciente al Segundo Estilo. El fragmento conserva el arranque de dos semicírculos desde la base del molde a los que acompañan hileras de ángulos, y entre ellos cuatro estrellas de ocho puntas con círculo interior (fig. 7).

Esta decoración, a base de estrellas de ocho puntas y círculo interior, la recoge López Rodríguez asociada a los característicos círculos dobles ${ }^{29}$.

La marca de propiedad aparece de nuevo bajo la zona decorada. Se trata de un aspa grabada postcocción por medio de incisión. En este caso el artesano insiste por segunda vez en el grabado, razón por la que hemos denominado a su propietario el alfarero de la doble aspa.

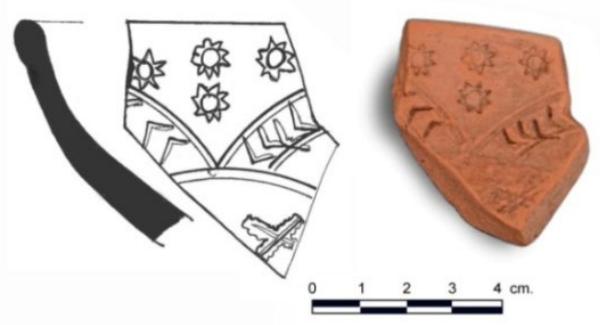

Figura 7. Fragmento con marca de doble aspa. Molde 64. Figura 30.

\subsection{El alfarero del aspa simple}

Ejemplar con decoración perteneciente al Segundo Estilo. Conserva el arranque de dos semicírculos a los que acompañan hileras de ángulos con trazado paralelo, completa la decoración una hilera de ángulos con trazado vertical (fig. 8).

Es una decoración muy elemental que puede relacionarse con varios modelos recogidos por López Rodríguez ${ }^{30}$. La marca del molde es un aspa sencilla y fue creada por medio de incisión postcocción.

29. José Ramón LÓPEZ RODRÍGUEZ: Terra sigillata hispánica..., fig.17, 3A, 13/2.

30. Ibid., fig.16, 3A, $1 / 2$ y $1 / 3$. 


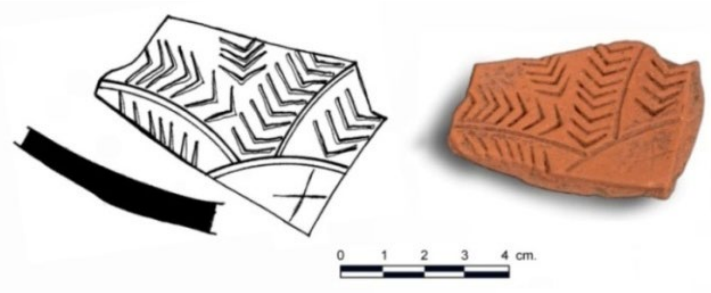

Figura 8. Fragmento con marca de aspa simple. Molde 62. Figura 30.

\subsection{El alfarero de la roseta estrellada}

El último ejemplar es un fragmento de molde con motivos decorativos del Segundo Estilo (fig.9). Conserva el arranque de dos semicírculos a los que acompañan hileras de ángulos. En el fondo del molde fueron impresas precocción dos rosetas con aspecto estrellado y círculo interior.

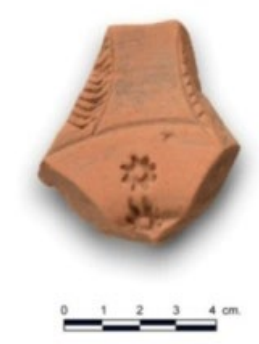

Figura 9. Fragmento con dos rosetas. Molde 68. Figura 32.

La doble marca insiste una vez más en la tendencia a mostrar la propiedad del molde. Además, en este caso la roseta inferior quedó impresa en el fondo del molde, lo que hace imposible atribuirle una función decorativa.

\subsection{Soportes y otros vestigios de alfar}

Entre los vestigios arqueológicos que permiten identificar una actividad alfarera en este asentamiento se encuentran los soportes (carretes), utilizados para montar el horno y la cocción de la vajilla (fig. 10).

Han sido recuperados seis ejemplares completos y un sétimo fragmentado. El elemento a destacar en estos útiles es la pervivencia de su tipología, pues son similares a los utilizados en época imperial. 


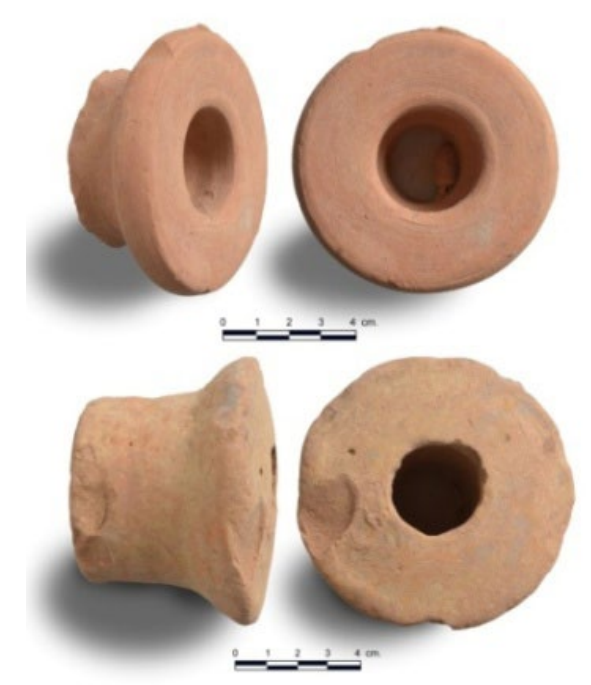

Figura 10. Dos ejemplos de soportes recuperados en Sobrevilla.

Y merecen ser comentados cuatro fragmentos cerámicos salpicados de arcilla. Suponemos que proceden de vasos fracturados tras finalizar el proceso completo de su fabricación, incluido el engobado y la cocción. Rotas estas piezas, de manera fortuita, sus fragmentos serían arrojados próximos al torno alfarero o junto a las pilas de decantación, a modo de vertedero o escombrera provisional, donde quedarían salpicados al manipular la arcilla durante nuevas producciones.

En cualquiera de los casos, el hecho de que aparezcan en el mismo contexto que los moldes permite incorporarlos al conjunto de vestigios de la industria alfarera (Fig. 11). 

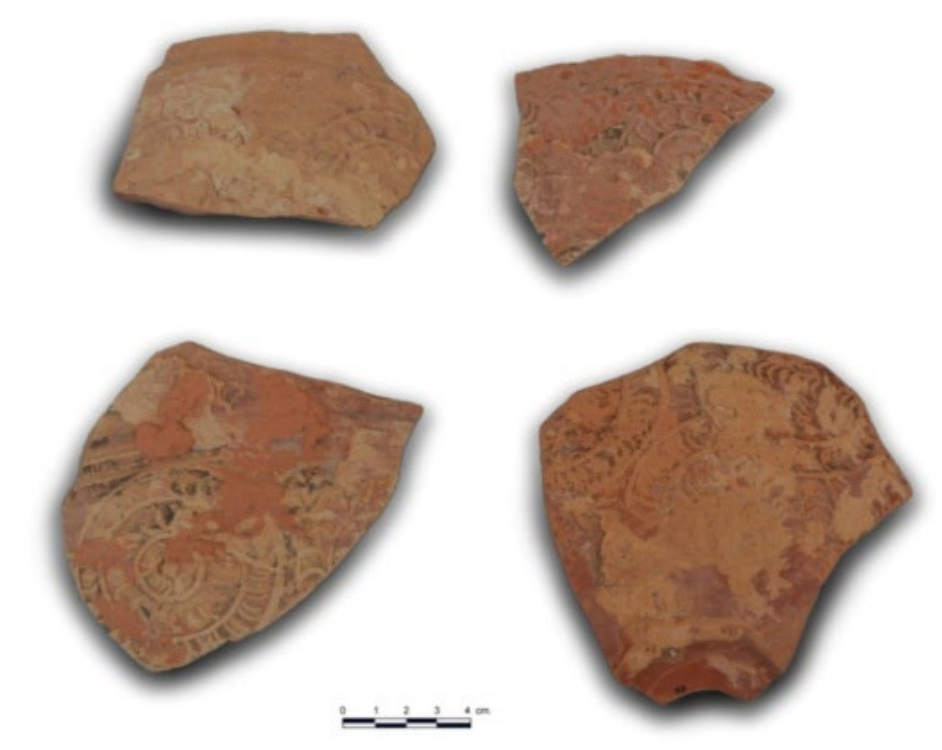

Figura 11. Fragmentos de TSH tardía decorada portadores de barros postcocción.

\section{Una hipotética ruta comercial en el valle del Ebro}

En las figuras 22 y $22 \mathrm{~A}$ de nuestro inventario se incluye el fragmento de molde número cuarenta. En su friso inferior pueden verse, formando decoración seriada, una roseta, un motivo vertical, difícil de describir por su mal estado de conservación, y entre ambos un tercer punzón poco conocido en la TSHT, aunque frecuente en las decoraciones de guirnaldas de la TSH.

López Rodríguez recoge este motivo en una de las tablas ${ }^{31}$ y en un fragmento decorado de la forma 37 tardía $^{32}$. Según este autor, el fragmento número 855 fue recuperado en las excavaciones arqueológicas realizadas en el paraje Árbol Blanco, término de Corella (Navarra) ${ }^{33}$.

Tomamos este ejemplo por ser un elemento decorativo poco frecuente en la cerámica tardía, particularidad que invita a plantear el estudio de una posible ruta comercial a lo largo del valle del Ebro. Esta ruta partiría del centro alfarero

31. José Ramón LÓPEZ RODRíGUEZ: Terra sigillata hispánica..., Fig. 8, nº 38.

32. Ibid., Lámina 48, nº 855.

33. Ibid., p. 190. 
de Sobrevilla para establecer una etapa en Corella y otros lugares de la Ribera de Navarra.

La ruta comercial seguiría aguas abajo del río Ebro para adentrarse en Aragón, donde también vamos a encontrar amplia información sobre el consumo de cerámica tardorromana, gracias al trabajo de Paz Peralta y otros investigadores más ${ }^{34}$.

Son varios los motivos decorativos publicados que pueden relacionarse con los moldes de Sobrevilla, pero nos limitamos a comentar unas rosetas de nuestro inventario, en concreto las del molde número 3 de las figuras 13 - 13A, cuyos motivos decorativos se aproximan a los que recoge Paz Peralta en el vaso número $279^{35}$. Pero como decíamos anteriormente, se trata simplemente de algunos ejemplos para su futura discusión.

\section{Conclusiones}

Los vestigios arqueológicos que damos a conocer en este artículo fueron recogidos por expertos en arqueología de campo, cabe citar a Pedro Rioja Rubio e Hilario Pascual González, David Bolaños Carmona, responsable de la sala museo del ayuntamiento de Badarán, y los autores de este artículo.

Somos conscientes de que este tipo de prospecciones visuales no permiten establecer cronologías definitivas, pero los materiales recuperados presentan evidencias que pueden considerarse orientativas.

Es el caso del fragmento de columna reutilizada como ara dedicada a las Matres Apillarae o el molde elaborado a mano alzada con escena de Artemis Diana, sin olvidar, claro está, el antoniano de mediados del siglo III, pues todos ellos evocan momentos tempranos del bajo imperio.

Es destacable también el grupo de moldes que ofrece nuestro inventario, ya que permite valorar la importancia del alfar teniendo en cuenta que los ciento treinta y un fragmentos que en él se recogen fueron localizados en un espacio reducido. También hay que destacar el hecho de que hasta esta publicación eran conocidos solamente diecisiete fragmentos de molde procedentes de Sobrevilla.

Las marcas de alfarero descubiertas constituyen también otra interesante aportación, pues refuerza la hipótesis planteada hace años sobre la posible existencia en Sobrevilla de un centro alfarero donde pudieron estar activos hasta siete hornos para la fabricación de $\mathrm{TSHT}^{36}$, cuestión esta última que lógicamente deberán confirmar futuras intervenciones arqueológicas.

34. Juan Ángel PAZ PERALTA: Cerámica de mesa de los siglos III al VI d. C...

35. Ibid., fig. 48, p. 135.

36. María Pilar PASCUAL MAYORAL, P. RIOJA RUBIO y Pedro GARCÍA RUIZ: "El centro alfarero de Sobrevilla...", p. 296. 
Y nos parece necesario resaltar su variada decoración, cuyos motivos decorativos permitirán ser contrastados con los abundantes materiales cerámicos recuperados por otros investigadores en excavaciones arqueológicas, así como el estudio de posibles rutas comerciales que desde la zona media del río Najerilla comunicaron diversos territorios del valle del Ebro, alto Duero o de Navarra y el País Vasco a lo largo del bajo Imperio.

\section{Bibliografía}

ABAD LEÓN, Felipe: Historia viva del Seminario nuevo de Logroño: 75 años dando buen fruto, Logroño, Diócesis de Calahorra y La Calzada-Logroño, 2004.

BERIGISTAIN GÚRPIDE, María Amor y CASTIELLA RODRÍGUEZ, Amparo: “La colección Julio Rodríguez del Seminario Diocesano de Logroño", en Javier CAÑADAS SAURA (coord.): Miscelánea de arqueología riojana, Logroño, Instituto de Estudios Riojanos, 1973, pp. 163-196.

CASTILLO PASCUAL, María José: “Una dedicatoria a las Matres en Badarán (La Rioja)", Hispania Antiqua, 23 (1999), pp. 137-141.

GARABITO, Tomás y SOLOVERA, María Esther: "Tritium Magallum y el valle del Najerilla en el bajo Imperio: Hallazgos arqueológicos", en Ángeles ALONSO ÁVILA (coord.): Homenaje al profesor Montenegro: estudios de historia antigua, Valladolid, Universidad de Valladolid, Secretariado de Publicaciones e Intercambio Editorial, 1999, pp. 691-718.

IÑIGO ERDOZAIN, Lidia y MARTÍNEZ GONZÁLEZ, Milagros: "Nuevo alfar de 'Terra Sigillata' hispánica tardía en el valle medio del Najerilla (Cañas, La Rioja)", Iberia: Revista de la Antigüedad, 5 (2002), pp. 217-274.

LÓPEZ RODRÍGUEZ, José Ramón: Terra sigillata hispánica tardía decorada a molde en la Península Ibérica, Valladolid, Secretariado de Publicaciones, Universidad, 1985.

MARTÍNEZ GONZÁLEZ, Milagros y VITORES BAÑARES, Saúl: "Yacimientos romanos en los entornos de Berceo y Badarán (La Rioja)", Iberia: Revista de la Antigüedad, 2 (1999), pp. 239-273.

MARTÍNEZ GONZÁLEZ, Milagros y VITORES BAÑARES, Saúl: "Nuevos alfares de 'Terra Sigillata' hispánica tardía en el entorno de Tritium Magallum (Badarán y Berceo, La Rioja)”, Iberia: Revista de la Antigüedad, 3 (2000), pp. 333-372.

MAYET, Françoise: Les céramiques sigillées Hispaniques. Contribution à I'histoire economique de la Péninsule Ibérique sous I’Empire romaín, París, Publications du Centre Pierre, 1984.

PASCUAL MAYORAL, María Pilar, RIOJA RUBIO, P. y GARCÍA RUIZ, Pedro: "El centro alfarero de Sobrevilla. Badarán, La Rioja", Antigüedad y Cristianismo: Monografías históricas para la Antigüedad Tardía, 17 (2000), pp. 291-312. 
PAZ PERALTA, Juan Ángel: Cerámica de mesa romana de los siglos III al VI d.C. en la provincia de Zaragoza, Zaragoza, Institución Fernando el Católico, 1991.

PÉREZ RODRÍGUEZ-ARAGON, Fernando: "La 'terra sigillata' Hispánica Tardía: Una propuesta de sistematización", en Carmen FERNÁNDEZ OCHOA, Ángel MORILLO CERDÁN y María del Mar ZARZALEJOS PRIETO (coords.): Manual de la cerámica romana. IV producciones cerámicas de época medio imperial y tardorromana, Madrid, Museo Arqueológico de la comunidad de Madrid, Colegio de Doctores y Licenciados en Filosofía y Letras y en Ciencias de la Comunidad de Madrid, 2019, pp. 65-134.

ROMERO CARNICERO, María Victoria et al.: "El centro de producción de cerámica de Uxama (Osma/El Burgo de Osma, Soria)", en Société Française d'Étude de la Céramique Antique en Gaule (SFECAG): Actes du Congrès de L'Escala-Empúrie, Marseille, SFECAG, 2008, pp. 319-330.

ROLDÁN HERVÁS, José Manuel: Itineraria Hispana: Fuentes antiguas para el estudio de las vías romanas en la Península Ibérica, Valladolid, Departamento de Historia Antigua, Universidad de Valladolid, 1975.

SÁENZ PRECIADO, Juan Carlos: "Los alfares de época tardorromana del valle del río Najerilla (siglos IV-VI d.C.)", Berceo, 128 (1995), pp. 113-157. 


\section{INVENTARIO DE MOLDES PROCEDENTES DEL ALFAR DE SOBREVILLA}

Mostramos a continuación el catálogo - inventario de los moldes recuperados en el centro alfarero de Sobrevilla compuesto, como ya se dijo, por ciento treinta y un fragmentos de molde de TSHT.

De todo el conjunto disponible, hemos decidido dibujar y fotografiar sesenta y siete fragmentos; cuarenta y tres del Primer Estilo y veinticuatro del Segundo Estilo, ya que los motivos decorativos de los sesenta y cuatro restantes son punzones repetidos, como consecuencia de la monótona decoración de esta cultura material.

Queda por comentar que, debido a las comprensibles normas de publicación de las revistas científicas, hemos decidido agrupar varias figuras en las páginas donde mostramos dibujos y fotografías de los moldes. Se presentan en línea los dibujos y las fotografías correspondientes y se mantiene la numeración de cada figura tratando de mostrar con mayor rigor la proporción de los moldes respecto a las escalas que en cada una de ellas se acompañan.

Como ayuda a posteriores consultas del grupo de moldes recuperados en el alfar de Sobrevilla, adelantamos un pequeño comentario sobre cada una de las figuras que esperamos sirva a futuros investigadores.

\section{Figuras: $12-12 \mathrm{~A}$}

Molde número 1. Fragmento decorado a mano alzada con escena mitológica. Conserva busto femenino con diadema o creciente lunar, ciervo y pájaro. El conjunto decorativo es asociado a las diosas Artemis - Diana ${ }^{37}$. Al dorso, es legible entre molduras, la firma incompleta del alfarero CARDIVS, grafitada con técnica de incisión postcocción.

Es el único ejemplar conocido de este estilo en el alfar de Sobrevilla. Es difícil establecer una cronología, aunque la calidad de la decoración permite situarla en época temprana, quizás hacia el siglo III cuando suponemos comienza la actividad industrial en este yacimiento.

\section{Figuras: $13-13 \mathrm{~A}$}

Moldes números 2 - 4. Fragmentos con motivos del Primer Estilo. El fragmento 2 muestra una interesante decoración distribuida en dos frisos. El friso superior con rosetas seriadas y el inferior combina elementos faunísticos y palmetas.

Los círculos de línea sinuosa con rosetas o círculos en su interior que aparecen en estos moldes son frecuentes en el mundo tardío. Motivos decorativos $1 \mathrm{~A}-1 \mathrm{~B}^{38}$.

37. Ibid., pp. 311-312.

38. José Ramón LÓPEZ RODRIGUEZ: Terra sigillata hispánica..., p. 55. (Para referirnos a los motivos decorativos seguiremos en adelante la clasificación de José Ramón López Rodríguez, 1985) 


\section{Figuras: $14-14 \mathrm{~A}$}

Números 5 - 10. Fragmentos con motivos decorativos del Primer Estilo. Aparecen círculos de línea sinuosa y círculos de línea cortada, portadores de rosetas con pétalos cuadrangulares.

\section{Figuras: $15-15 \mathrm{~A}$}

Números 11 - 14. Fragmentos con motivos decorativos del Primer Estilo. Conservan motivos decorativos similares a los que vimos en láminas anteriores.

\section{Figuras: $16-16 \mathrm{~A}$}

Números 15 - 20. Fragmentos con motivos decorativos del Primer Estilo. El punzón mayoritario es la roseta de pétalos cuadrangulares, formando en ocasiones decoración seriada.

En el molde número 18 aparecen sobre los motivos seriados pequeñas rosetas estrelladas próximas al borde. Y el número 20 muestra decoración seriada de círculos concéntricos de línea simple, con pequeñas medias lunas en su interior.

\section{Figuras: 17 - 17A}

Números 21 - 26. Fragmentos con motivos decorativos del Primer Estilo. Círculos de línea sinuosa, línea quebrada y línea simple, con rosetas de pétalos cuadrangulares y rosetas simples. Su decoración seriada alterna con motivos verticales tipo palmeta.

El motivo decorativo vertical del molde número $21(1 \mathrm{C} / 26)$ se aproxima al que aparece en el molde 23 aunque creado este último en posición horizontal tratando de formar una decoración cruciforme o quizás grandes cuadros.

El motivo vertical del molde 22 se asemeja a los recogidos por López Rodríguez en la lámina 38, n 664; lámina 40, nº 696 y lámina 52, nº 929. Completan la decoración dos tipos de rosetas, formando parte de ellas decoración seriada.

\section{Figuras: $18-18 \mathrm{~A}$}

Números 27 - 29. Fragmentos con motivos decorativos del Primer Estilo. Decoración seriada en los tres casos, a base de motivos verticales. El del molde 27 se aproxima al motivo 2A1, 40; El del número 28 a 1C, 19 y 23; y el del molde 29 al motivo 1C, 24. 


\section{Figuras: $19-19 \mathrm{~A}$}

Números 30 - 32. Fragmentos con motivos decorativos del Primer Estilo. La decoración de estos moldes se realiza a base de círculos y rosetas, de las que ya hemos hablado, y motivos verticales. El motivo vertical de los moldes 30 y 31 lo tenemos en 1C, 24; y el del molde 32 en 2A1, 35.

\section{Figuras: $20-20 \mathrm{~A}$}

Números 33 - 35. Fragmentos con motivos decorativos del Primer Estilo. Los fragmentos pertenecen a dos bordes y una base. Portan motivos vegetales del tipo 2A1, 60, separando figuras difíciles de describir.

En el molde 33 la decoración se organiza en tres frisos. En el friso superior la palmeta parece separar motivos faunísticos. En el segundo friso no podemos precisar la figura, mientras que el tercero conserva decoración con cuatro círculos concéntricos.

El molde número 34 presenta dos frisos. En el superior dos palmetas y entre ellas un posible motivo flamígero. En el inferior un pequeño detalle que podríamos relacionar con el remate $2 \mathrm{~B}, 24$.

El molde número 35 conserva restos de palmeta similar a las anteriores, probablemente invertida.

\section{Figuras: $21-21 \mathrm{~A}$}

Números 36 - 38. Fragmentos con motivos decorativos del Primer Estilo. Pertenecen a un borde y dos arranques desde la base.

El número 36 presenta decoración seriada. En la moldura superior cinco remates de pequeños semicírculos concéntricos, y bajo ellos una serie de palmetas separando tres motivos vegetales o quizás flamígeros.

Los moldes 37 y 38 muestran también temas seriados, compuestos por figuras humanoides y palmetas. En $2 \mathrm{~A} 3$ se recogen varios motivos humanoides, descritos por López Rodríguez como motivos figurados, pero ninguno de ellos coincide con los aquí descritos.

\section{Figuras $22-22 \mathrm{~A}$}

Números 39 - 41. Fragmentos con motivos decorativos del Primer Estilo. Son tres fragmentos de borde. El molde 39 presenta decoración dudosa que puede asociarse a un punzón de ángulo, aunque la escena completa sugiere una bandada de pequeñas aves.

El número 40 muestra decoración en dos frisos. En el superior una serie de rosetas separadas por motivos verticales, recogidos en 1C, 18; en el friso 
inferior decoración seriada con roseta y punzón, frecuente en la decoración de guirnaldas de la sigillata imperial (TSH). Puede consultarse en 1C, 38.

El molde 41 conserva figura humanoide seriada, similar a la catalogada en 2A3, 13. La decoración está rematada en la parte superior del borde con pequeños círculos de línea sencilla y roseta de pétalos cuadrangulares.

\section{Figuras: $23-23 \mathrm{~A}$}

Molde número 42. Fragmento con motivos decorativo del Segundo Estilo. Concentra cien medias lunas y diez círculos. Corresponde a la parte inferior del molde y su decoración se realiza en tres frisos.

El friso superior aparece tímidamente y muestra dos medias lunas. El intermedio es decorado con semicírculos paralelos, rellenos de medias lunas en su interior, y completan el conjunto círculos de línea simple en el exterior; el friso inferior está decorado completamente con medias lunas.

\section{Figuras: $24-24 \mathrm{~A}$}

Números 43 - 45. Fragmentos con motivos decorativos del Segundo Estilo. El número 43 corresponde a un fragmento de borde, el 44 un fragmento del cuerpo o pared y el 45 a un fragmento que arranca de la base. Están decorados con grandes círculos paralelos que integran pequeños círculos, motivo $3 \mathrm{~A}$.

\section{Figuras: $25-25 \mathrm{~A}$}

Números 46 - 48. Fragmentos con motivos decorativos del Segundo Estilo. El número 46 corresponde al borde del molde, el 47 al cuerpo o pared y el 48 al arranque desde la base. La decoración está creada a base de grandes semicírculos y círculos dobles, que integran medias lunas y pequeños círculos.

Tenemos varios ejemplos de su decoración en $3 \mathrm{~A}, 2 / 1,2 / 2,2 / 3$ y en $3 \mathrm{~A}$, $11 / 1$, y siguientes.

Cabe destacar el error del alfarero al trazar los semicírculos superiores del molde 46 y el posterior intento por solucionarlo con el punzón de media luna. Son errores interesantes, puesto que si aparece un fragmento con esta peculiar decoración será muy difícil rebatir la procedencia.

\section{Figuras: 26 - 26A}

Números 49 - 53. Fragmentos con motivos decorativos del Segundo Estilo. De nuevo decoraciones de grandes semicírculos y dobles círculos acompañados de medias lunas. Los números 50, 52 y 53 conservan los orificios del compás, el 50 decorado con media luna y el 53 con pequeño círculo. 


\section{Figuras: $27-27 \mathrm{~A}$}

Números 54 - 55. Fragmentos con motivos decorativos del Segundo Estilo. Se repiten una vez más las decoraciones de dobles círculos con medias lunas. Ambos fragmentos corresponden al arranque desde la base.

El número 54 presenta un círculo fuera del friso destinado a la decoración. No se trata de un fallo del alfarero sino, como ya se dijo, de una marca creada para demostrar, ante posibles pérdidas o confusiones, la propiedad del molde.

\section{Figuras: $28-28 \mathrm{~A}$}

Números 56 - 57. Fragmentos con motivos decorativos del Segundo Estilo. Son dos bordes de molde decorados con modelos similares a otros anteriores.

El número 56 es rematado con hilera de medias lunas a lo largo del borde. Bajo esta hilera se traza un círculo simple de gran tamaño y se decora su interior con hileras radiales de medias lunas. Los grandes círculos son separados por hileras verticales de medias lunas.

La decoración del número 57 es más sencilla, aunque tan elegante como la del anterior. Se realiza a base de grandes círculos concéntricos y semicírculos dobles, con hileras de medias lunas en su interior.

\section{Figuras: $29-29 A$}

Números 58 - 61. Fragmentos con motivos decorativos del Segundo Estilo. Los moldes 58, 59 y 60 corresponden al borde y el número 61 a la base.

Decoración elaborada con grandes semicírculos y círculos dobles de gran tamaño, con hileras de ángulos en su interior. Tenemos algunos paralelos en $3 \mathrm{~A}$, $1 / 1,1 / 2,1 / 3$.

\section{Figuras: $30-30 \mathrm{~A}$}

Números 62 - 65. Fragmentos con motivos decorativos del Segundo Estilo. Presentan mayoritariamente decoraciones geométricas a base de grandes dobles círculos que integran hileras de ángulos.

El molde 62 conserva fuera de la zona decorada un aspa sencilla, que hemos asociado con una marca creada por el alfarero para mostrar su propiedad. En los moldes 64 y 65 se completa la decoración con rosetas estrelladas y círculo simple en su interior. 


\section{Figuras: $31-31 \mathrm{~A}$}

Números 66 - 67. Fragmentos con motivos decorativos del Segundo Estilo. La tendencia decorativa a base de grandes círculos incorpora en ocasiones barras de línea ondulada similares a las de 2A1, 10, y trazados de línea ondulada distribuidos en partes diferentes del molde, como sucede en Lámina $108, n^{\circ} 2089$.

\section{Figuras $32-32 \mathrm{~A}$}

Números 68 - 71. El número 68 es parte de la base del molde. Conserva el arranque de dos grandes círculos acompañados de hilera de ángulos. Bajo la zona decorada, pueden verse dos rosetas estrelladas que hemos relacionado con marcas de propiedad.

Los números 69 y 70 son fragmentos que asociamos a un mismo molde. Como ya se dijo, los elementos verticales alternan con rosetas y bajo la escena decorativa aparece un grafito creado postcocción cuya epigrafía está por confirmar.

El fragmento número 71 forma parte de la base del molde. Presenta un pequeño vestigio decorativo que puede relacionarse con hilera de ángulos. En la zona lisa, cerca ya de la base, puede verse una roseta decapétala con círculo central marcado, que también hemos asociado a una marca de propiedad. 

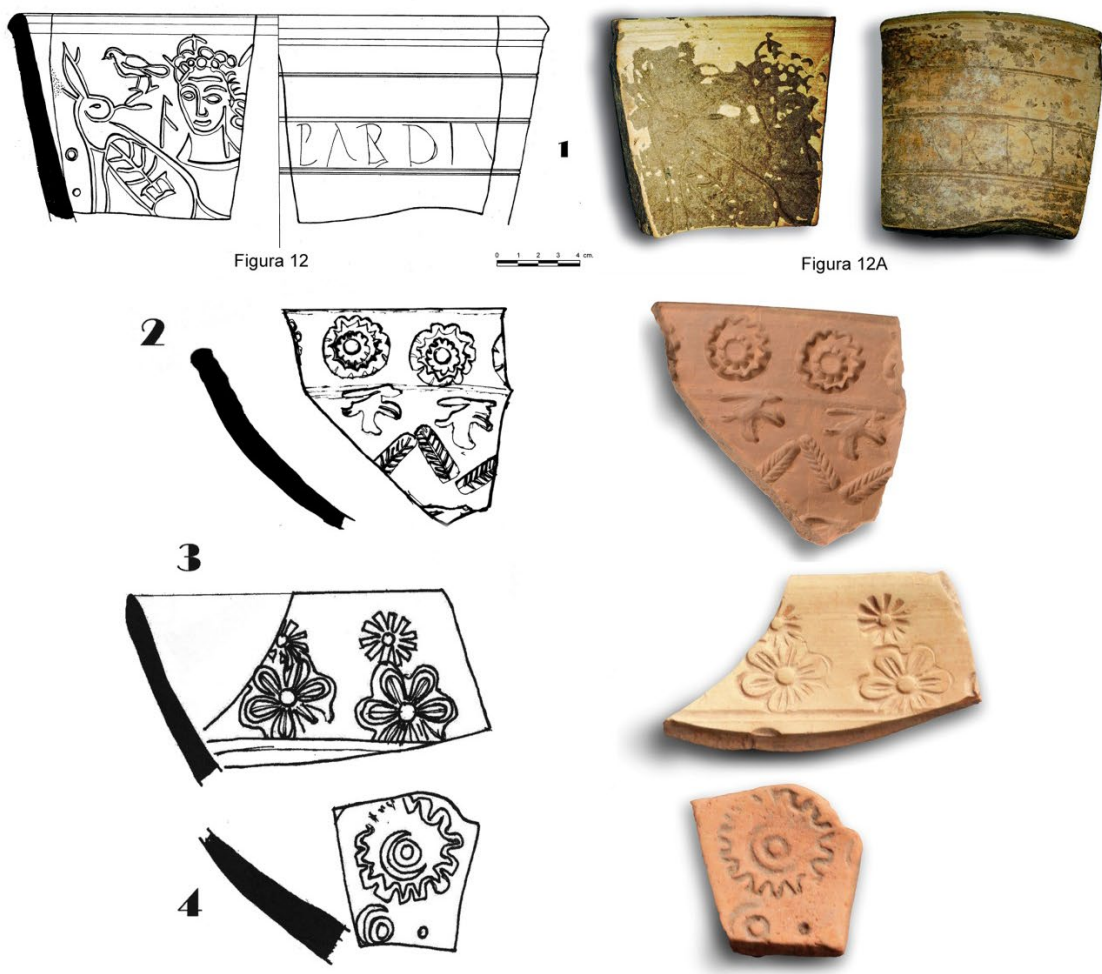

Figura 13
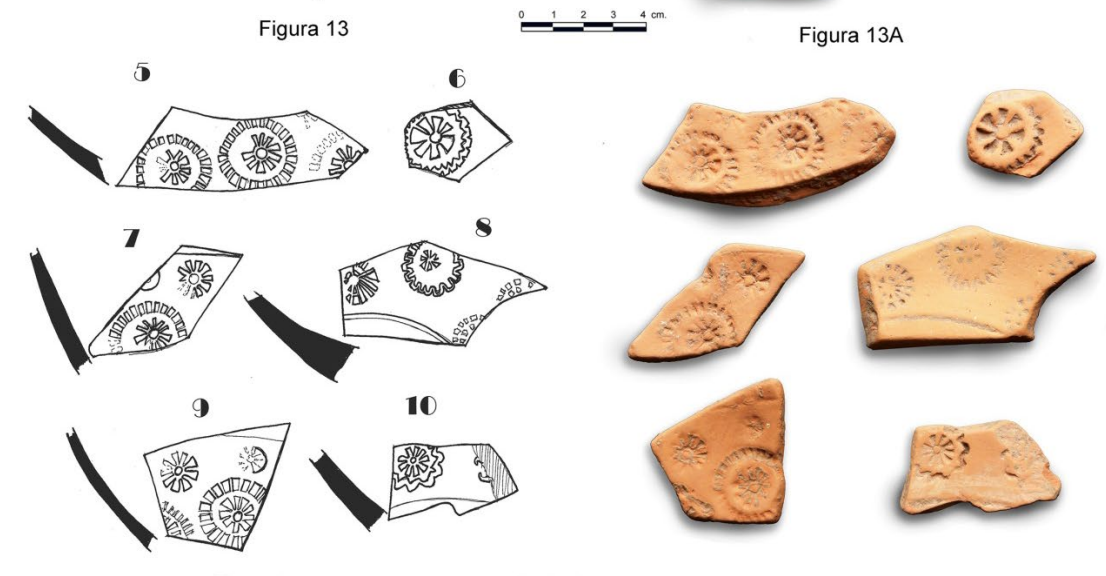

Figura 14
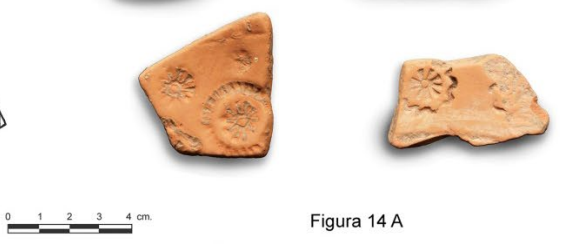

Figuras 12 - 12A; 13 -13A; 14 - 14A. Moldes: 1 - 10. 

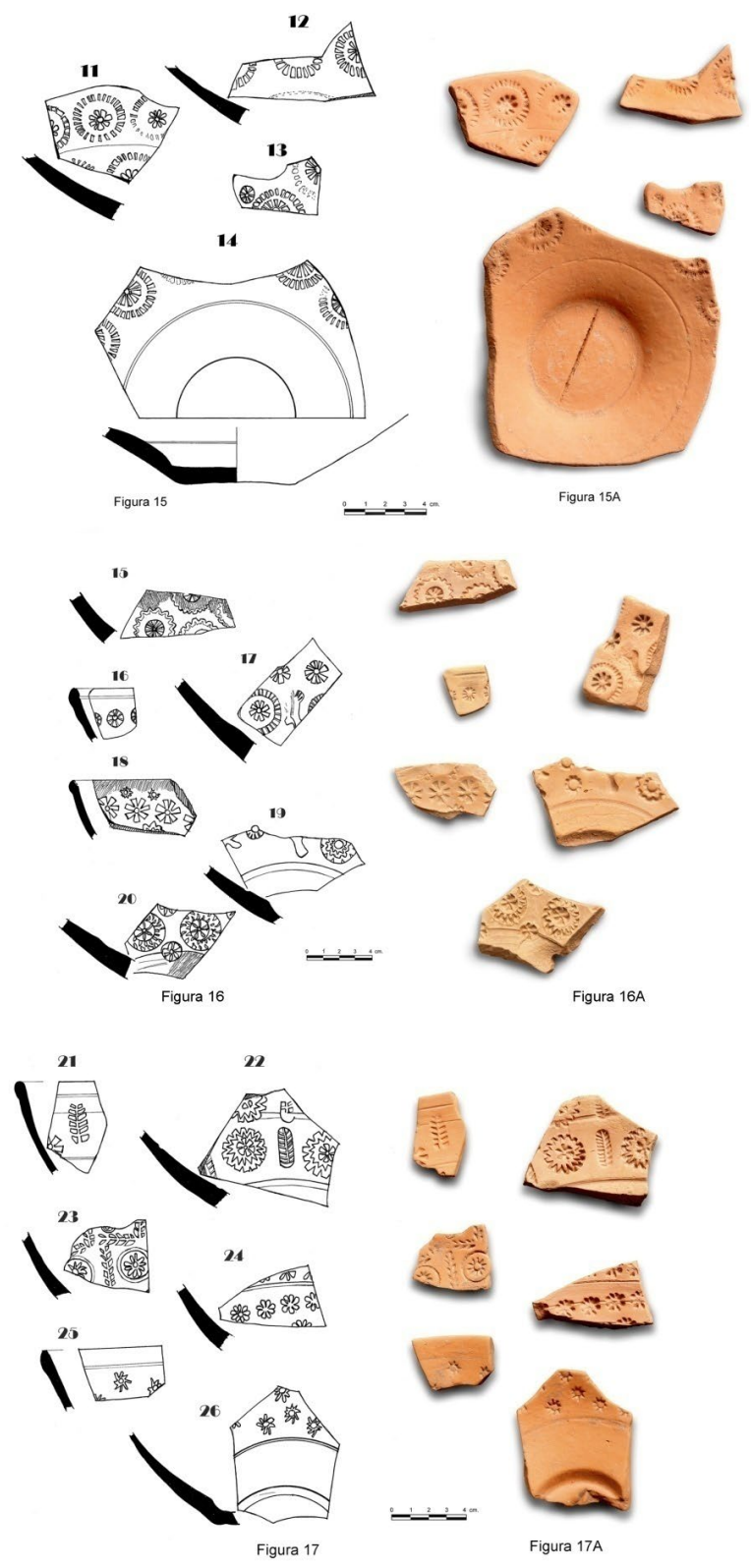

Figuras 15 - 15A; $16-16 \mathrm{~A} ; 17$ - 17A. Moldes: $11-26$. 


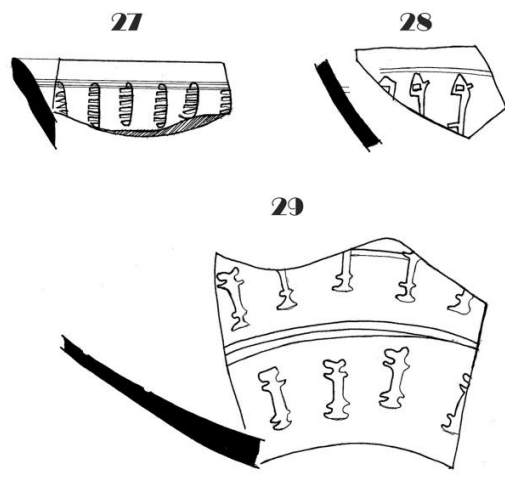

Figura 18
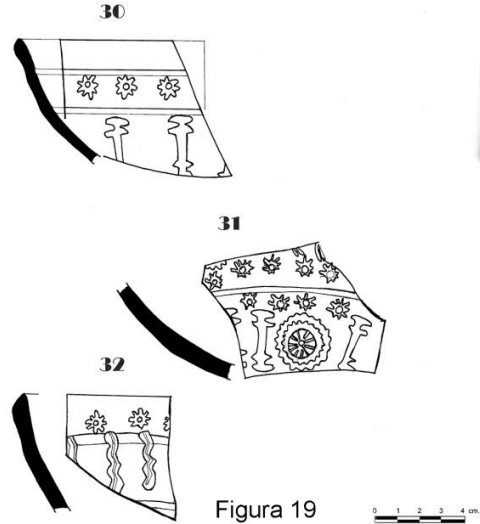

33

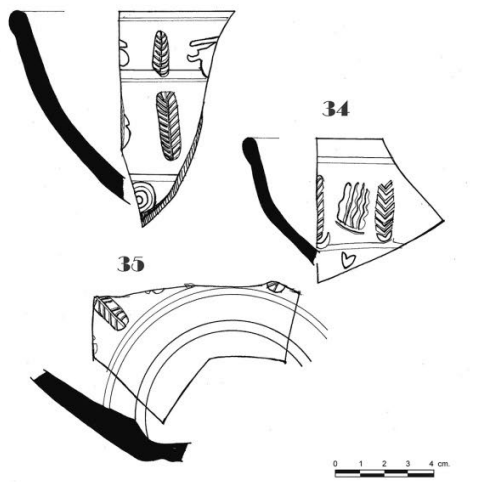

Figura 20
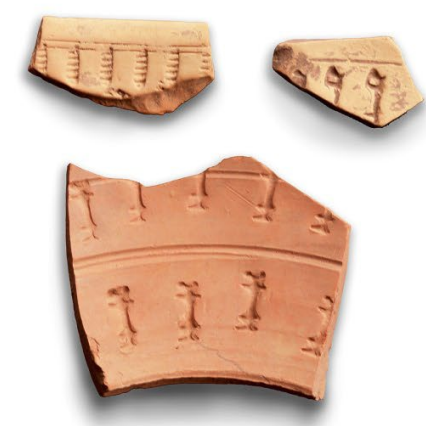

Figura 18A
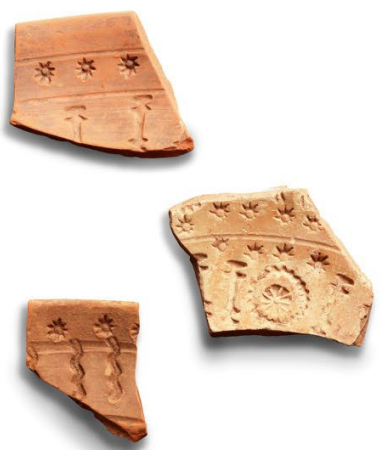

Figura 19A
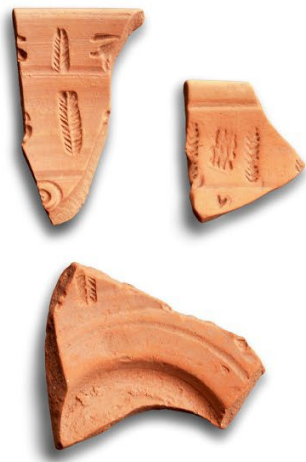

Figura 20A

Figuras 18 - 18A; 19 -19A; 20 - 20A. Moldes: $27-35$. 


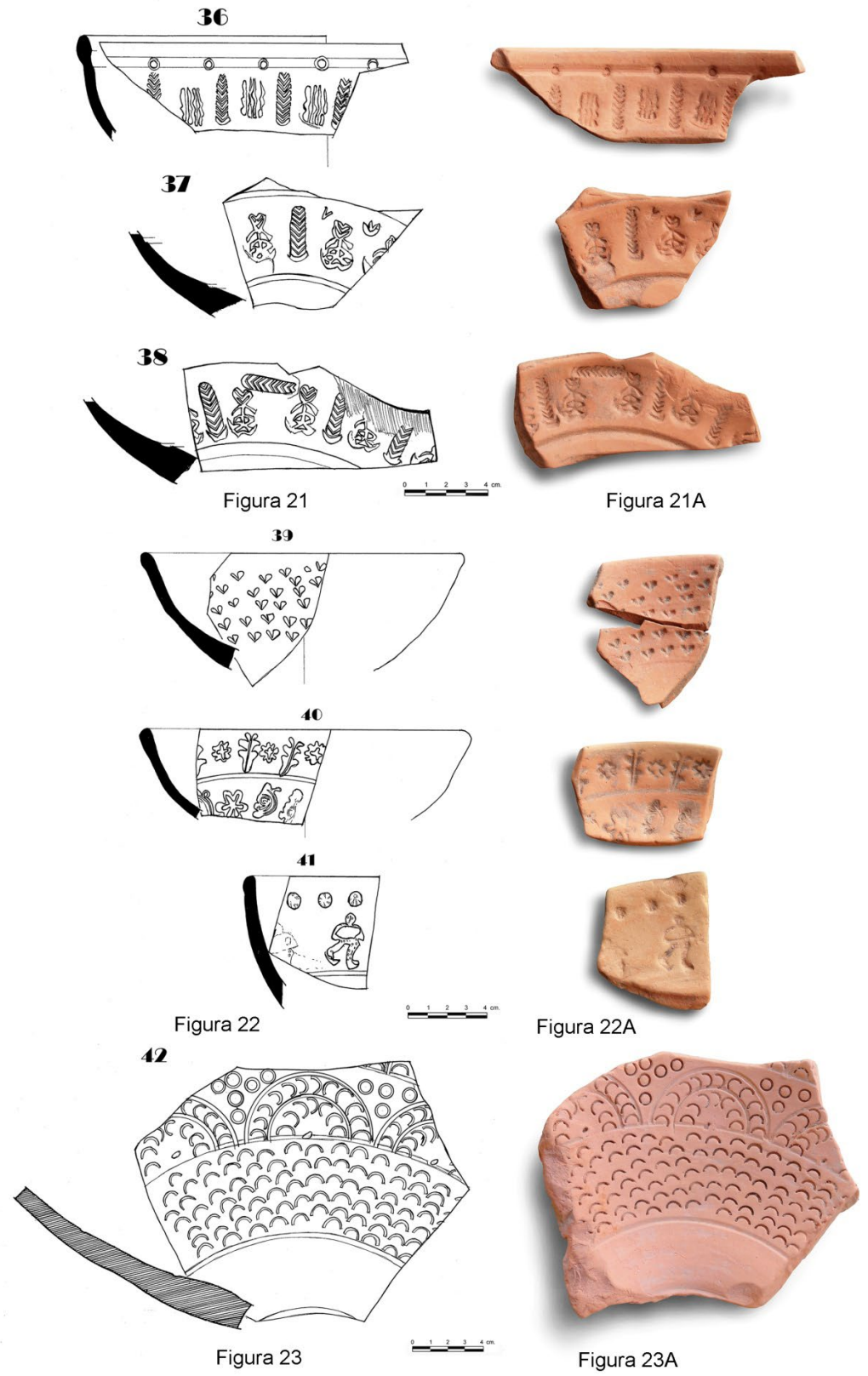

Figuras $21-21 \mathrm{~A} ; 22-22 \mathrm{~A} ; 23-23 \mathrm{~A}$. Moldes: $36-42$. 
43
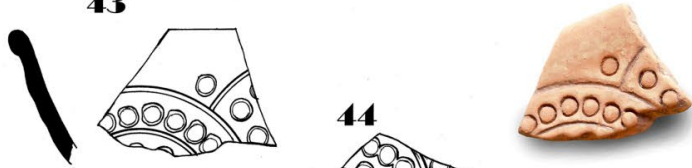

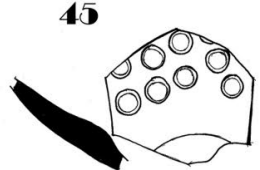

Figura 24

46

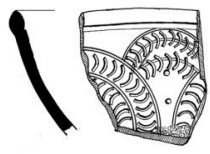

47
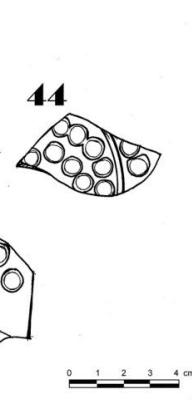

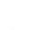

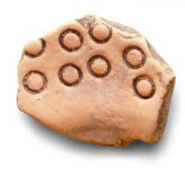

Figura 24A
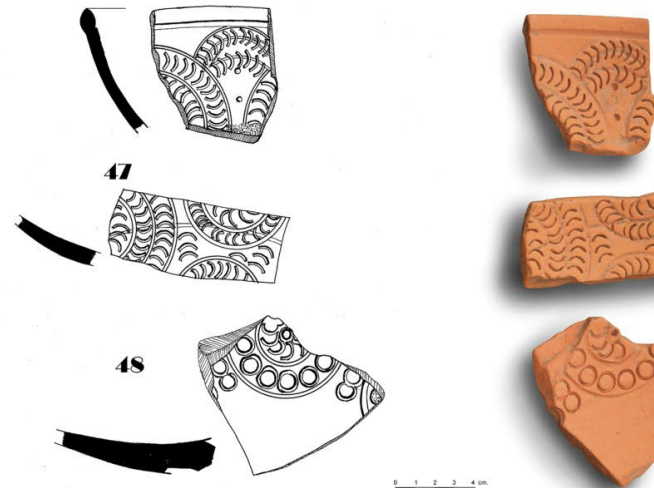

Figura 25

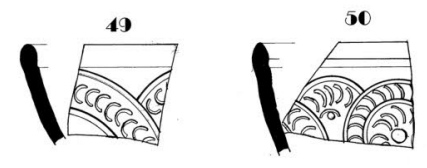

51
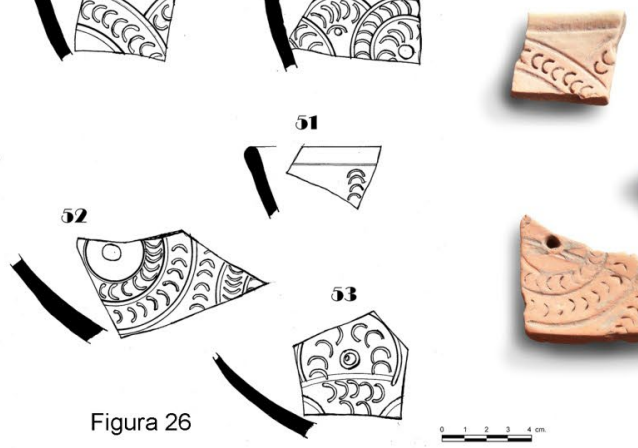

Figura 25A
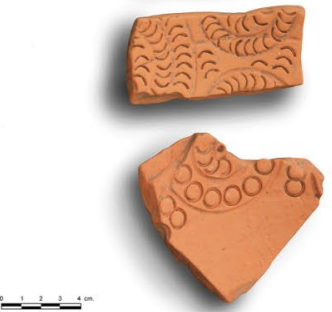

Figura 26

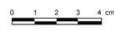

Figura 26A

Figuras 24 - 24A; 25 - 25A; 26 - 26A. Moldes: 43 - 53. 

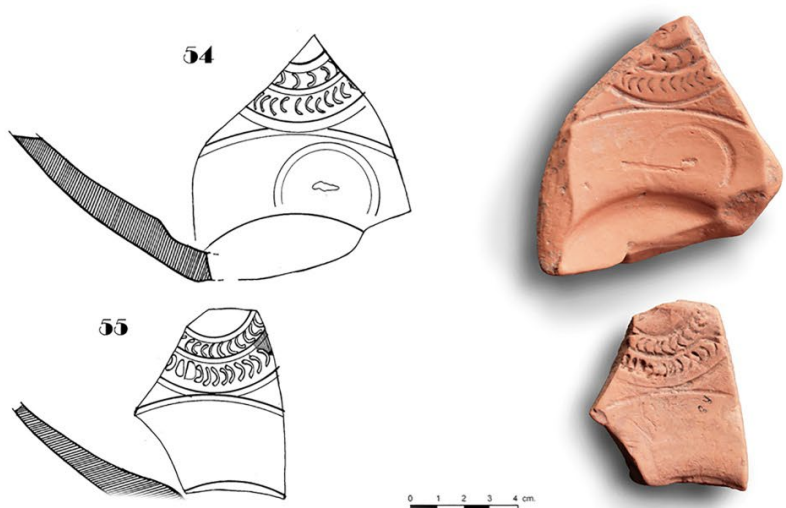

Fgura 27

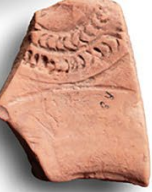

Figura 27A
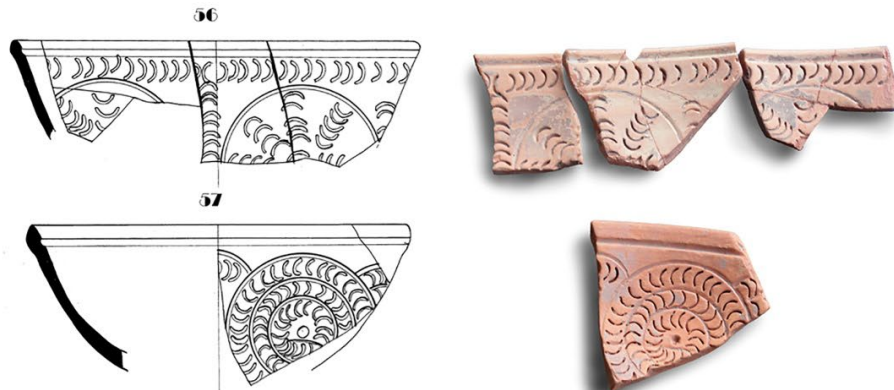

Fgura 28
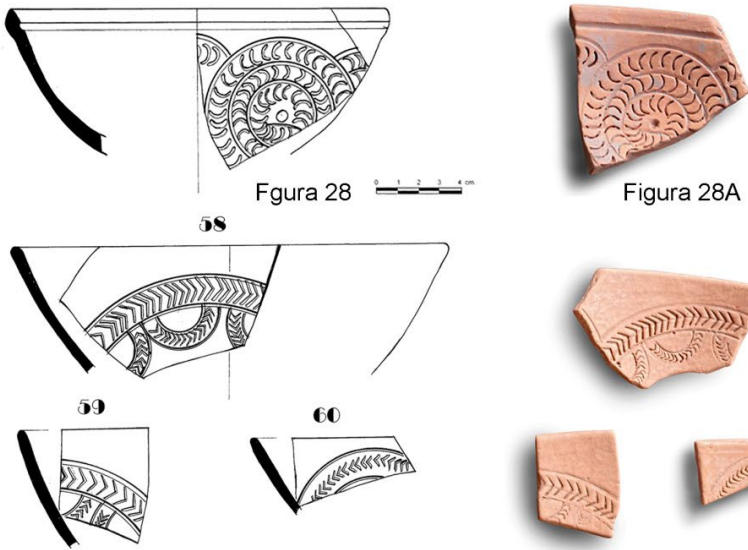

(5)

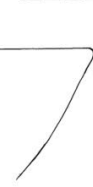

Figura 28A

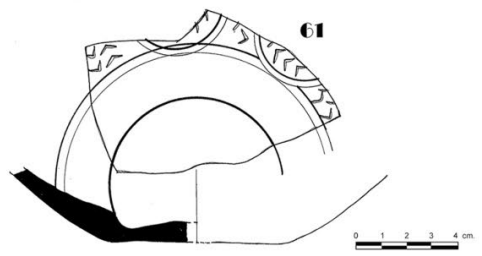

Fgura 29
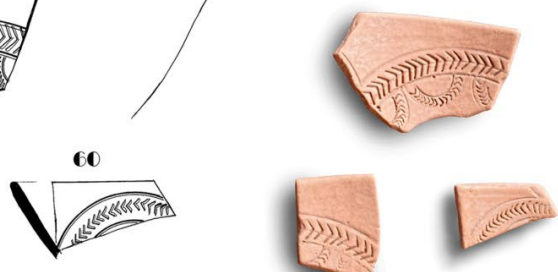

FIGURAS $27-27 \mathrm{~A} ; 28-28 \mathrm{~A} ; 29-29 \mathrm{~A}$. Moldes: $54-61$. 


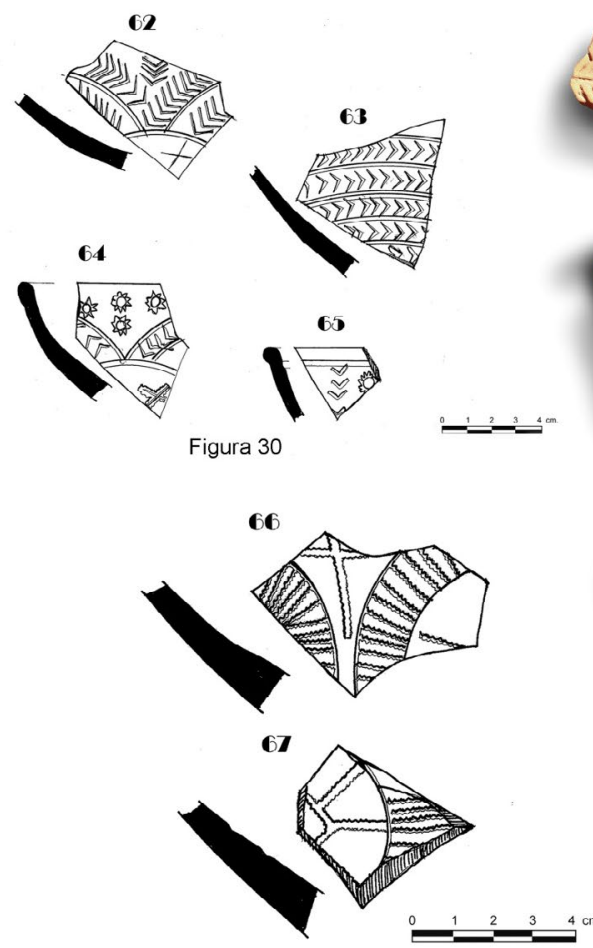

Figura 31
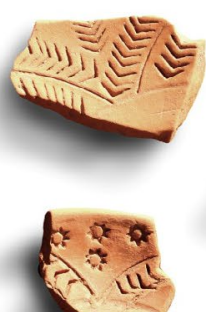

(1)......

(I)

(2)गया।

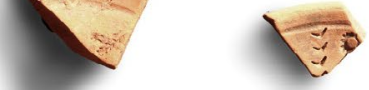

Figura 30A
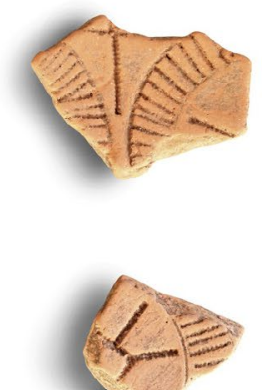

Figura $31 \mathrm{~A}$

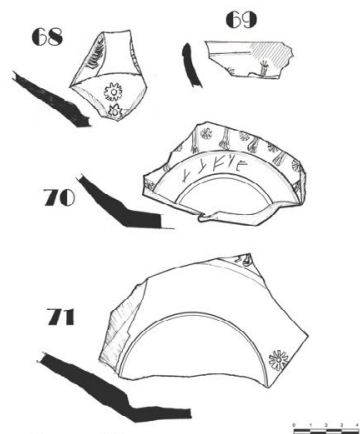

Figura 32

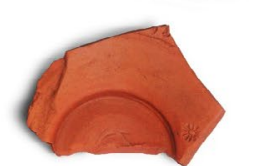

Figura $32 \mathrm{~A}$

Figuras 30 - 30A; 31 - 31A; 32 - 32A. Moldes: $62-71$. 